\title{
Shift happens: trailing edge contraction associated with recent warming trends threatens a distinct genetic lineage in the marine macroalga Fucus vesiculosus
}

Katy R Nicastro ${ }^{\dagger}$, Gerardo I Zardi ${ }^{* \dagger}$, Sara Teixeira, João Neiva, Ester A Serrão and Gareth A Pearson

\begin{abstract}
Background: Significant effects of recent global climate change have already been observed in a variety of ecosystems, with evidence for shifts in species ranges, but rarely have such consequences been related to the changes in the species genetic pool. The stretch of Atlantic coast between North Africa and North Iberia is ideal for studying the relationship between species distribution and climate change as it includes the distributional limits of a considerable number of both cold- and warm-water species.

We compared temporal changes in distribution of the canopy-forming alga Fucus vesiculosus with historical sea surface temperature (SST) patterns to draw links between range shifts and contemporary climate change. Moreover, we genetically characterized with microsatellite markers previously sampled extinct and extant populations in order to estimate resulting cryptic genetic erosion.

Results: Over the past 30 years, a geographic contraction of the southern range edge of this species has occurred, with a northward latitudinal shift of approximately 1,250 km. Additionally, a more restricted distributional decline was recorded in the Bay of Biscay. Coastal SST warming data over the last three decades revealed a significant increase in temperature along most of the studied coastline, averaging $0.214^{\circ} \mathrm{C} /$ decade. Importantly, the analysis of existing and extinct population samples clearly distinguished two genetically different groups, a northern and a southern clade. Because of the range contraction, the southern group is currently represented by very few extant populations. This southern edge range shift is thus causing the loss of a distinct component of the species genetic background.

Conclusions: We reveal a climate-correlated diversity loss below the species level, a process that could render the species more vulnerable to future environmental changes and affect its evolutionary potential. This is a remarkable case of genetic uniqueness of a vanishing cryptic genetic clade (southern clade).
\end{abstract}

Keywords: Climate change, geographic boundaries, microsatellites, cryptic genetic erosion, sea surface temperature

\section{Background}

Global climate change has a profound influence on distributional patterns of a wide variety of taxa causing species range shifts and population extinctions [1,2]. Poleward movements in latitude or increases in altitude have been observed in several geographic regions and for many

\footnotetext{
* Correspondence: zardi73@yahoo.it

† Contributed equally

CCMAR - CIMAR Laboratório Associado, Universidade do Algarve - Campus de Gambelas, Faro, 8005-139 Portugal
}

species' ranges (for example, [3-6]) but the effects of contemporary climatic change at the so-called trailing edges have received considerably less attention.

Although several studies have addressed phylogeographic responses to millennial-scale climate variability [7], surprisingly few empirical studies have investigated how contemporary climate change on decadal scales impacts genetic diversity $[2,8]$. Climate-driven range reduction can have significant genetic and evolutionary consequences for surviving populations by decreasing 
genetic diversity and hindering a population's ability to adapt to future ecological disturbances (for example, [9]). Most studies investigating the effects of climate change on biodiversity consider a species as a unit and thus overlook intraspecific genetic variation. However, vulnerability to genetic depauperation depends on the geographical distribution of genetic diversity within a species; for those in which diversity is relatively homogeneous throughout the distributional range the genetic effect of range contraction is largely independent of which part of the range is lost (for example, $[8,10]$ ). However, genetic depletion will strongly depend on which part of the range is affected for species with a geographically skewed distribution of genetic diversity (for example, [11]).

Current geographical distribution of genetic diversity reflects both contemporary and historical events. Populations that are currently geographically peripheral may be particularly vulnerable to loss of genetic diversity because they are often restricted to decreasing habitat areas within unsuitable landscape. Their small size and prolonged isolation is accompanied by loss of within-population genetic diversity and increased inter-population genetic divergence due to increased random genetic drift, probability of suffering bottleneck effects, and reduced gene flow [12,13]. Previous climatic changes such as the glacial episodes of the Quaternary have left marked genetic signatures in present-day geographical distribution of genetic diversity. In particular, lower latitude regions where populations persisted through multiple glacial cycles (that is, glacial refugia), often host populations with higher genetic diversity than those in areas that were recolonized (for example, $[14,15]$ ). Importantly, marginal refugial populations that did not play a role in postglacial colonization processes have considerable conservation value because they may harbor unique genetic variation that is threatened by recent climate warming [16-18].

The stretch of Atlantic coast between North Africa and Iberia is ideal for the study of the relationship between marine species distribution and possible effects of climatic warming because a considerable number of both cold- and warm-water species reach their distributional limits within this stretch of coast (for example, [19-22]). In addition, several studies have described species distributional ranges and abundance clines since the middle of the 20th century in conjunction with abundant museum and herbarium data (for example, [22-30]), providing a solid historical background for studies aiming to describe changes in species distribution or abundance associated with environmental changes.

Surveys carried out in the last decade along the Atlantic Iberian Peninsula have correlated increasing sea surface temperature (SST) to striking expansion or contraction events [31-33]. SST is the prevailing factor controlling geographic distributions of many marine species at a latitudinal scale, either via direct effects on thermal tolerance or indirectly through changes in competition or predation dynamics [34-36]. While this is a recent worldwide trend, single-species response may be highly variable [5] and generalizations about poleward range shifts due to increasing temperature are not always possible $[37,38]$.

In this study, the model species selected was Fucus vesiculosus, an intertidal canopy-forming brown alga. The availability of records on the species distribution along North African and Iberian Atlantic shores and of DNA from recently extinct populations provides an ideal opportunity to investigate the impact of climatedriven range reduction on the overall species genetic diversity.

We investigate shifts in the southern distribution endpoints of $F$. vesiculosus during the last three decades along this stretch of coast. Resulting biogeographic dynamics are compared with SST warming trends in order to correlate range shifts with the intensity of climatic change in the region. We further draw on genetic data from extant populations and others that have recently become extinct (previously sampled) in a phylogeographic approach to test the extent to which unique genetic variation may be lost as a result of climate change and range contraction.

\section{Results}

\section{Past and present distributions and endpoints}

A literature review located the historical southern endpoint of F. vesiculosus in Southern Morocco at Khnifiss Lagoon (27 $59^{\prime} 40.82^{\prime \prime} \mathrm{N}-12^{\circ} 16^{\prime} 33.98^{\prime \prime W}$; Figure 1). Its presence at this location was last reported in 1985-1986 and it was also confirmed by the Institut Scientifique, Département de Botanique et d'Ecologie Végétale in Rabat (personal communication by Dr. Ibn Tattou Mohamed; see Additional file 1).

The southern endpoint is now positioned on the Portuguese west coast in the Tejo estuary $\left(38^{\circ} 45^{\prime} 38.99^{\prime \prime} \mathrm{N}, 8^{\circ}\right.$ $\left.56^{\prime} 28.43^{\prime \prime W}\right)$, representing an $11^{\circ}$ latitude shift $(1,250 \mathrm{~km}$ range contraction; Figure $2 \mathrm{~b})$. In addition, an isolated population was located in Cadiz-Puerto Real $\left(36^{\circ}\right.$ $\left.31^{\prime} 27.53^{\prime \prime} \mathrm{N}, 6^{\circ} 10^{\prime} 52.61^{\prime \prime W}\right)$ approximately in the middle of this range contraction and unattached vegetative fragments of adult $F$. vesiculosus were still observed entangled in Spartina grass in Ria Formosa $\left(37^{\circ} 00^{\prime} 36^{\prime \prime} \mathrm{N}, 7^{\circ} 59^{\prime} 31^{\prime \prime} \mathrm{W}\right)$, although the previously permanent and attached populations have totally disappeared from this coastal lagoon.

Historically, F. vesiculosus populations were reported along the whole Northern Iberian coastline, with the latest presences at north eastern locations dated from 1951 to 1988. Currently, a limited retreat of $70 \mathrm{~km}$ within the Bay of Biscay has occurred and the present endpoint is at

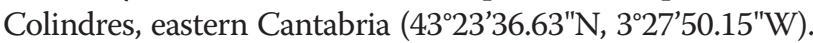




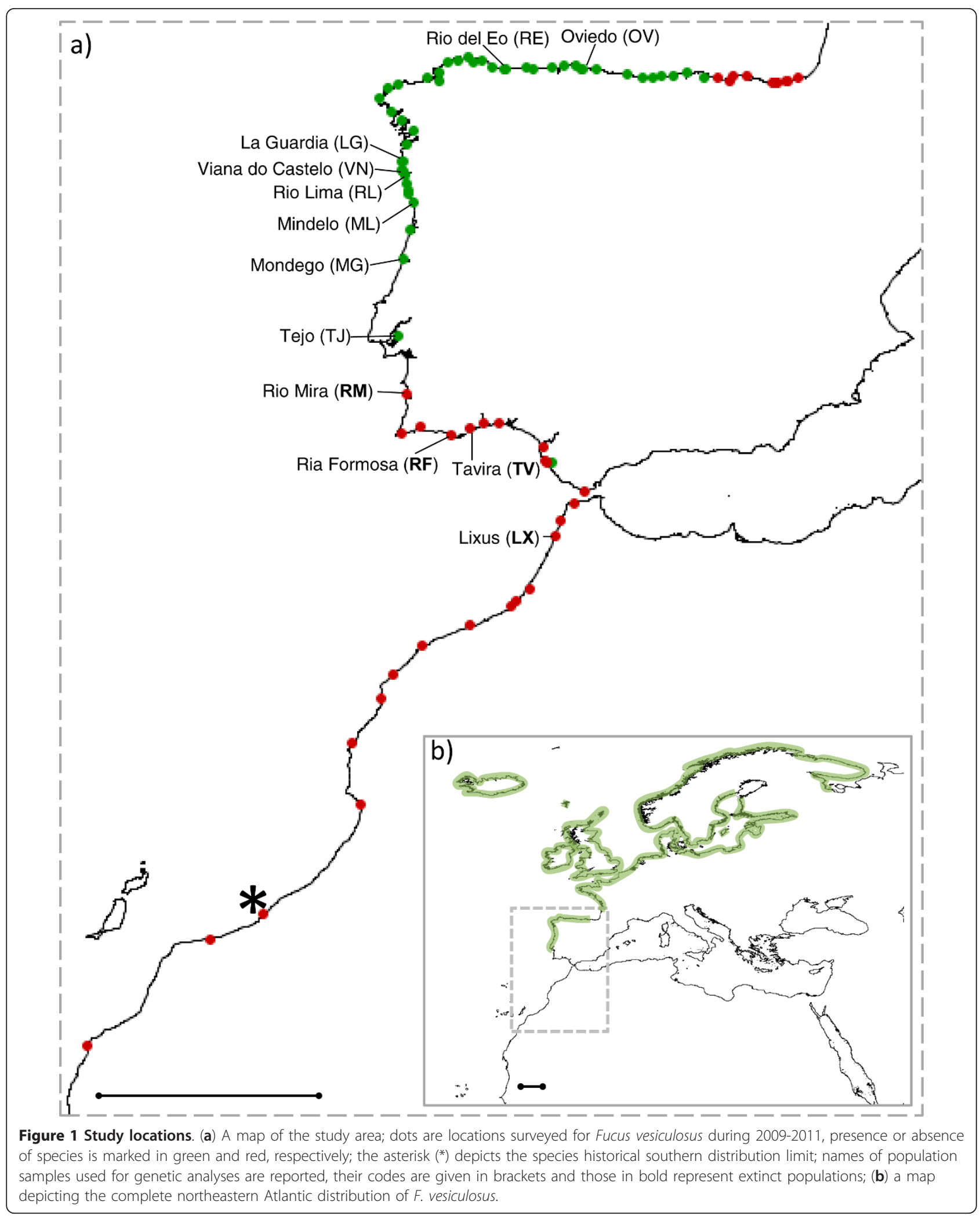




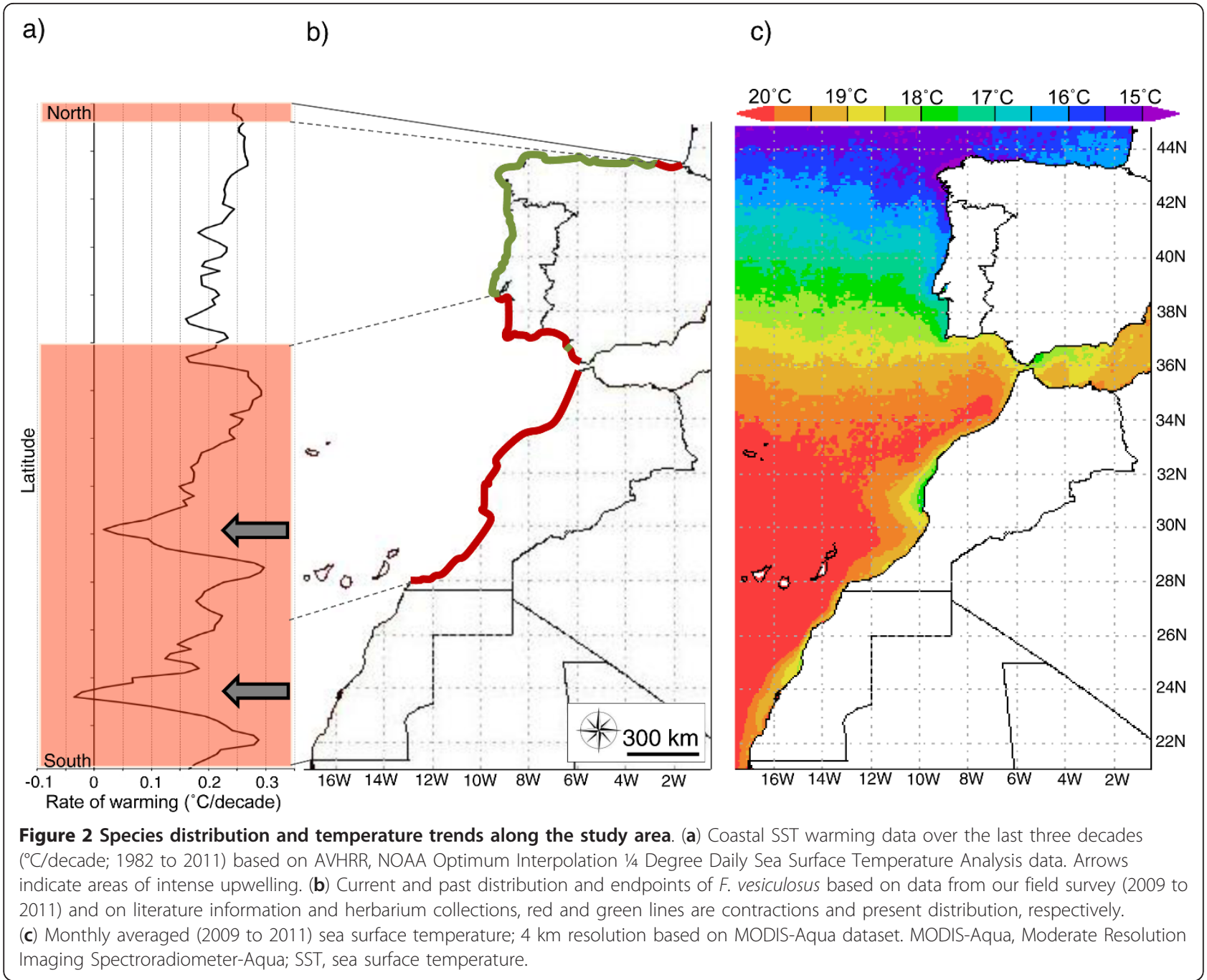

\section{Temperature trends}

Temperature isotherms shifted polewards to higher latitudes (Figure 2c). This gradient is interrupted by areas of strong and persistent upwelling. In particular, in Morocco, the constant upwelling off Cape Ghir (centered at $31^{\circ} \mathrm{N}$ ) generates a clear cold thermal intermission. Other upwelling cells are present to the south (Western Sahara), but fall outside the distributional range of $F$. vesiculosus. In contrast to North African shores, upwelling waters off north-west Iberian shores contribute to the SST gradient.

Over the last 30 years, a significant increase of coastal SST ( ${ }^{\circ} \mathrm{C} /$ decade; Figure $2 \mathrm{a}$ ) was observed throughout most of the entire Iberian and North African Atlantic coast. Coastal warming rates were not significant at relatively restricted areas within upwelling cells off Morocco (between $31^{\circ} 22^{\prime}$ and $32^{\circ} 22^{\prime}$ ) and Western Sahara (between $24^{\circ} 22^{\prime}$ and $\left.25^{\circ} 52^{\prime}\right)$. In non-upwelling areas, coastal SST warming ranged from 0.092 to $0.297^{\circ} \mathrm{C} /$ decade, with an average of $0.214^{\circ} \mathrm{C}$.

\section{Genetic analyses}

Previously sampled F. vesiculosus collected in 2001 and 2002 from 12 locations, including four extinct populations (Figure 1), were genotyped at five microsatellite loci. The whole dataset (668 individuals genotyped) was highly polymorphic and the total numbers of alleles per locus were: 17 (locus 20; Additional file 2), 8 (locus 58; Additional file 3), 11 (locus 94; Additional file 4), 14 (locus 78; Additional file 5) and 9 (locus 38; Additional file 6).

Allelic richness $(\hat{A})$ varied between 6.28 and 3.08 with lowest values for ML, RF, TV and LX, while unbiased heterozygosity $\left(H_{\mathrm{E}}\right)$ ranged between 0.381 and 0.587 with highest gene diversity values for RE, VN, RL and RM (location codes as reported in Figure 1). Observed heterozygosity $\left(H_{\mathrm{O}}\right)$ was significantly different from $H_{\mathrm{E}}$ in nine locations where heterozygote deficiency was detected, resulting in significant positive values of the inbreeding coefficient $F_{\text {IS }}$ (Table 1 ). The high values of $F_{\text {IS }}$ obtained were not locus dependent, indicating the markers used did 
Table 1 Genetic diversity of each population.

\begin{tabular}{lcccccc}
\hline Location & $\mathbf{N}$ & $\boldsymbol{H}_{\mathrm{E}}$ & $\boldsymbol{H}_{\mathrm{O}}$ & $\boldsymbol{F}_{\text {IS }}$ & $\hat{A}_{\mathbf{2 0}} \pm \mathrm{SD}$ & $\mathrm{UAN}$ \\
\hline OV & 21 & 0.489 & 0.498 & 0.009 & $4.76 \pm 0.089$ & 1 \\
RE & 29 & 0.587 & 0.401 & $0.336^{\mathrm{b}}$ & $6.28 \pm 0.303$ & 3 \\
LG & 48 & 0.420 & 0.342 & $0.197^{\mathrm{b}}$ & $5.12 \pm 0.335$ & 1 \\
VN & 94 & 0.583 & 0.509 & $0.132^{\mathrm{b}}$ & $4.52 \pm 0.415$ & 1 \\
$\mathrm{RL}$ & 48 & 0.571 & 0.377 & $0.349^{\mathrm{b}}$ & $5.04 \pm 0.358$ & 2 \\
ML & 48 & 0.486 & 0.388 & $0.213^{\mathrm{b}}$ & $3.44 \pm 0.434$ & 0 \\
MG & 96 & 0.457 & 0.437 & 0.050 & $4.20 \pm 0.200$ & 2 \\
TJ & 96 & 0.381 & 0.346 & $0.096^{\mathrm{a}}$ & $4.16 \pm 0.297$ & 1 \\
RM & 48 & 0.580 & 0.318 & $0.460^{\mathrm{b}}$ & $4.48 \pm 0.303$ & 0 \\
RF & 48 & 0.410 & 0.380 & 0.083 & $3.44 \pm 0.219$ & 0 \\
TV & 48 & 0.433 & 0.361 & $0.177^{\mathrm{b}}$ & $3.44 \pm 0.434$ & 1 \\
LX & 44 & 0.323 & 0.218 & $0.335^{\mathrm{b}}$ & $3.08 \pm 0.228$ & 0
\end{tabular}

$a^{a}<0.05$ and ${ }^{b}<0.001$ using 10,000 permutations. Codes correspond to locations in Figure 1 and are ordered from north to south, bold letters are extinct populations; $\mathrm{N}$, sample sizes; $H_{\mathrm{O}}$ and $H_{\mathrm{E}}$ observed and expected heterozygosity; $F_{\mathrm{IS}}$ inbreeding coefficient with significant values. $\hat{A}_{20}$, mean allelic richness normalized to the smallest sample size; SD, standard deviation of $\hat{A}_{20}$; UAN, unique allelic number.

not display technical issues such as null alleles. Unique alleles were detected for 8 of the 12 populations and varied between one and three.

Strong differentiation among populations was found as estimated by pairwise genetic differentiations $F_{\mathrm{ST}}$ and $D_{\text {EST }}$ values $(10,000$ permutations, $P<0.01$ for all comparisons, see Additional file 7; all confidence intervals do not overlap with zero, see Additional file 8). Pairwise differentiation was lower within two subgroups (hereafter 'northern' group: OV, RE, LG, VN, RL, ML; and 'southern' group: MG, TJ, RM, RF, TV, LX; location codes as reported in Figure 1 ). However, $D_{\text {EST }}$ estimates were particularly high between RE and all the other locations whereas LX and TJ had the lowest divergence.

On the basis of the dimensions scores of the Correspondence Analyses (CA), populations were grouped into two major clusters corresponding to the northern and the southern subgroups (Figure 3a). The first axis explains mostly the variance between these two clades (34.86\%), while the second and third axes mainly illustrate the differentiation within the two subgroups (13.48\% and $11.77 \%$, respectively). Overall, the northern group had a higher inter-population diversity, which is illustrated by the more scattered distribution of the points in the plot. The CA is consistent with the tree topology based on allele frequencies using Cavalli Sforza and Edwards' chord distance (Figure 3b), where two main branches were resolved. The first of these two subgroups comprised six populations (northern group). A second subgroup (southern group) consisted of six populations, two of which are still present at the locations while the rest are now extinct. This major genetic subdivision was supported by the results obtained with STRUCTURE, which revealed the most significant increase at $\Delta \mathrm{K}=2$ clusters (Figure $4 \mathrm{a}$ ), thereafter $\Delta \mathrm{K}$ remained unchanged. We concluded that $\mathrm{K}=2$ is the most likely number of genetic clusters (Figure $4 \mathrm{~b}$ ).

The northern group had many unique alleles, but the southern cluster including the now extinct populations also displayed unique alleles. This cluster suffered diversity loss with the recent extinctions, but still retains unique diversity (three unique alleles detected in five loci assessed, at MG, TJ; Table 2).

\section{Discussion}

A rapid and extensive range contraction of the southern border of a marine intertidal species occurred, with a northward shift of the historical limit of about $11^{\circ}$ latitude. This remarkable distributional shift consists of a latitudinal reduction of about $23 \%$ of the entire species range along eastern Atlantic shores and has resulted in the erosion of a cryptic evolutionary lineage at this trailing edge. Additionally, the range contraction is consistent with significant increases in SST throughout most of the coastal area studied.

\section{Range shift in southern Iberia}

Systematic shifts in geographical ranges of species and increased extinction risk has emerged as one of the most pervasive biological responses to recent anthropogenic climate warming. The general trend shows range expansion towards higher latitudes; however, redistribution dynamics at southern range margins are less clear (for example, [5]). While on land, southern or 'trailing' range boundaries of terrestrial ectotherms may not shift consistently towards the poles with climate warming, marine species ranges match more closely their limits of thermal tolerance. Thus, range shifts will show a more predictable southern range contraction in the marine realm [4].

Extinction of southern edge populations along the Iberian Peninsula has been reported for other marine cold temperate species [17]. Another study conducted along this stretch of coast highlights the complexity in making generalizations about range shifts for intertidal species [37]. The extensive historical records reviewed in our study indicate that until the late 1980s abundant populations of $F$. vesiculosus were still present along the entire Moroccan and Iberian Atlantic coasts, while in the early 2000s extensive populations of this alga still persisted in southern Portugal. When these records are compared with our more recent surveys (2009 to 2011), a major contraction of the southern range margin of this keystone intertidal species (that is, from southern Morocco to central Portugal, latitudinal reduction of more than $1,200 \mathrm{~km}$ ) is revealed. Taken together with past studies, there is a strong indication that the northward distributional shift along the Portuguese coast occurred very recently, probably within the last decade. 

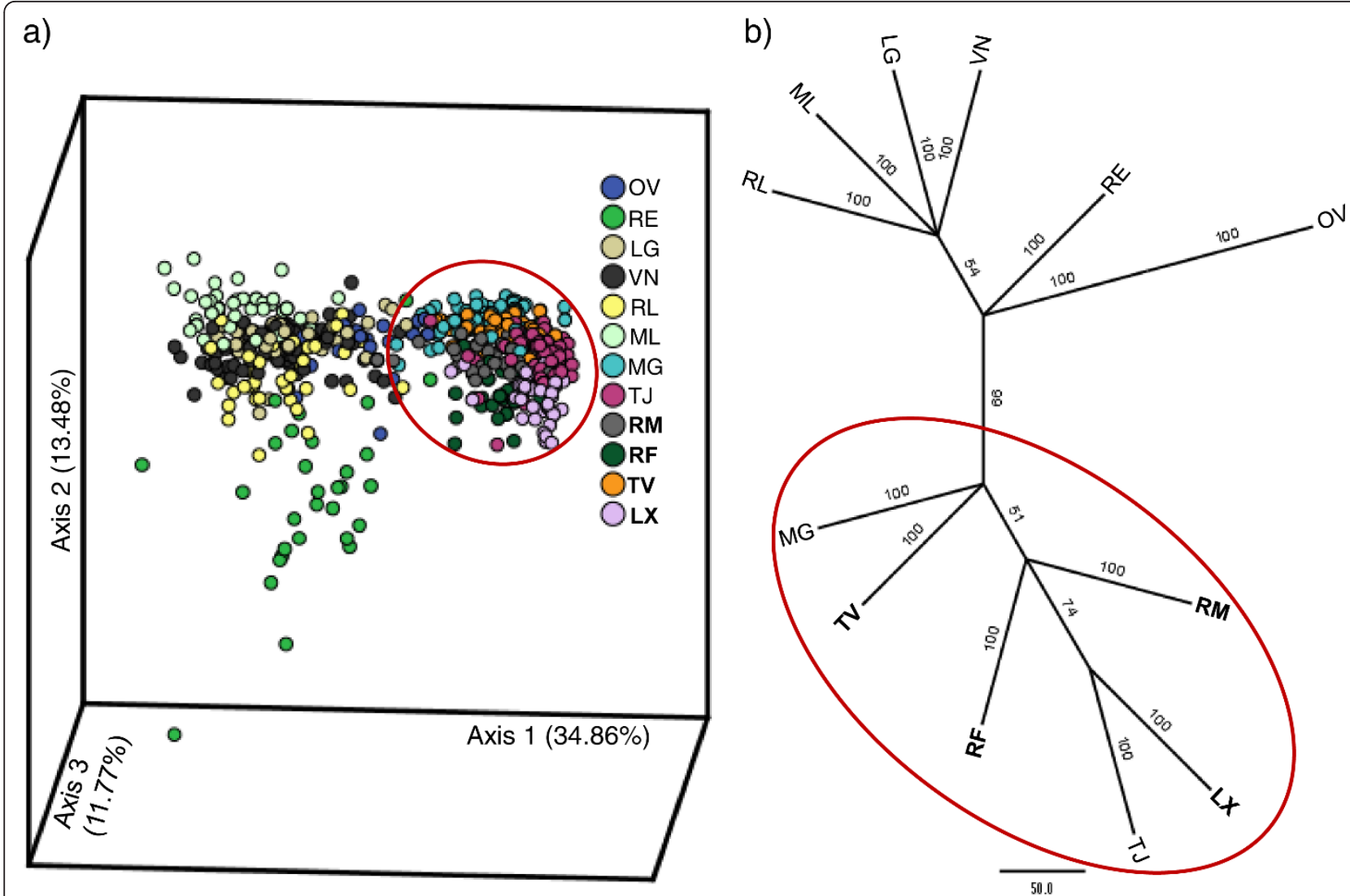

Figure 3 Correspondence Analyses and Neighbor-Joining tree. (a) Correspondence Analyses based on allele frequencies at five microsatellite loci. Percentages of inertia are shown between parentheses for each axis. (b) Neighbor-Joining tree inferred from Cavalli-Sforza and Edwards's pairwise distances; only bootstrap values higher than 50 are shown. Codes correspond to locations in Figure 1, locations belonging to the southern lineage are encircled and extinct populations are shown in bold.

This range contraction is an order of magnitude larger than the range shifts recorded for other species over the last 50 years along the Northeast Atlantic (for example, $[31,37])$.

Trends in SST indicated that the large scale disappearance of southern populations of F. vesiculosus is correlated with warming of North African and southwest Iberian coastal waters, with steady year-round increases averaging $>0.2^{\circ} \mathrm{C} /$ decade over the last three decades. Seasonal thermal extremes might also play a crucial role in defining the distribution of species through sudden population declines or die-offs [39]. However, the key pressure exerted by increasing average SST may result from sub-lethal rather than catastrophic effects. In the North-Eastern Atlantic, the distributional limits of most warm and cold-water algal species seem to be set by sub-lethal effects of water temperature, through reduced reproduction and growth, rather than by lethal effects $[34,40]$. Several other factors indirectly related or unrelated to changes in temperature may be responsible for the observed distributional shifts. These include biotic interactions (for example, grazing and competition [41]) and near-shore abiotic or anthropogenic effects (for example, pollution, coastal erosion, wave $[38,42])$. Moreover, seaweed survival, growth, and reproduction are known to be largely affected by latitudinal variations in nutrient supply $[43,44]$. However, mean or maximum water temperatures appear to be the best overall predictors of mortality events in the intertidal zone and the main determinants of large scale range contractions (for example, [36,45-47]) as opposed to maximum air temperatures. Intertidal organisms are essentially at the same temperature as water during high tide, while thermal conditions experienced during low tide are more likely to be affected by individual physiological $[48,49]$ and behavioral [50] capacities and by the heterogeneity of intertidal microhabitats [51,52].

The abundance of species is generally expected to peak at the center of their distributional range and decline with adverse conditions towards the range limits (for example, [53]). However, several empirical studies have challenged the 'abundant center' view of species distribution [54], such as in the intertidal zone where localized variations in the thermal environment due to 


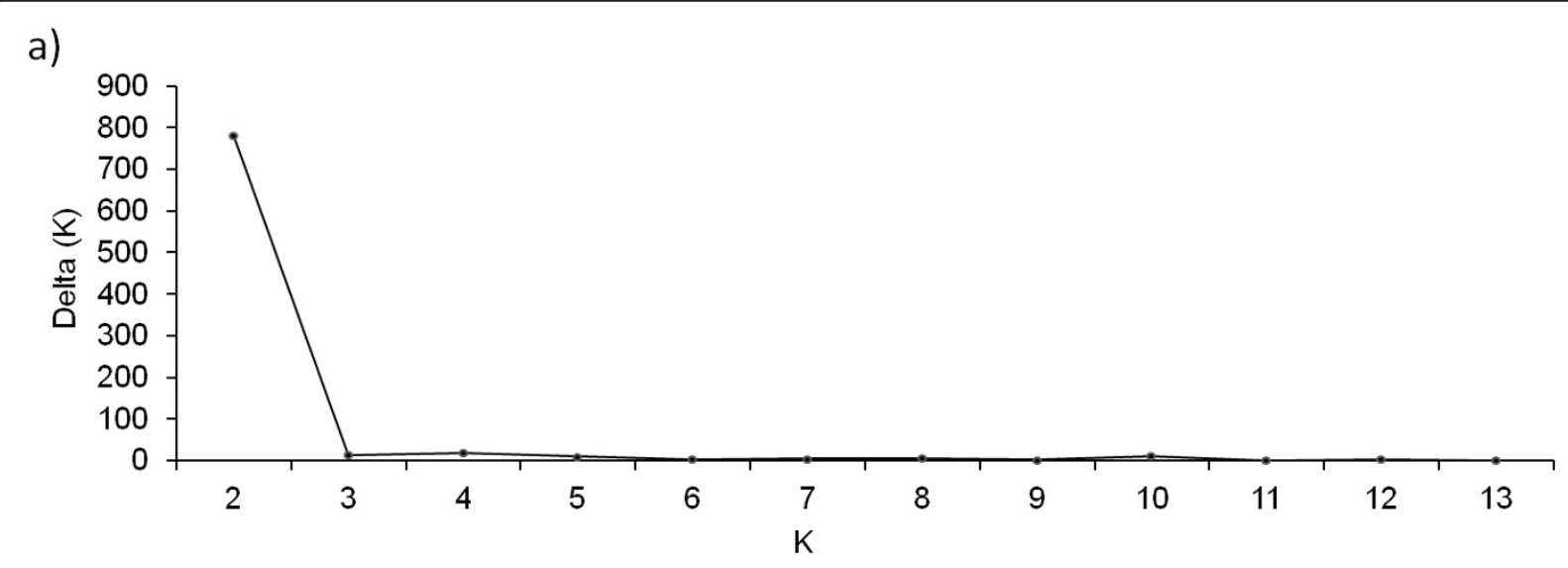

b)

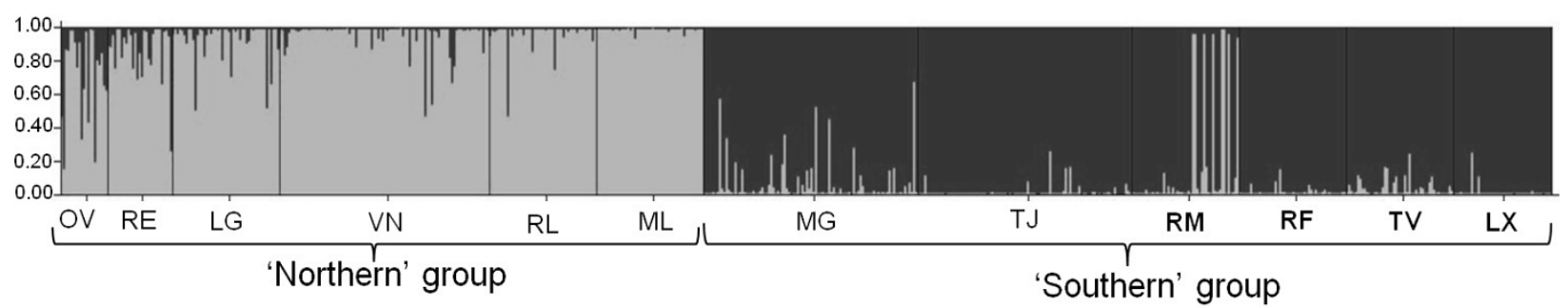

Figure 4 Histogram of STRUCTURE assignment of genotypes to clusters. (a) Plot of deltaK (an ad hoc statistic based on the rate of change in the log probability of data between successive $K$ values and used to predict the real number of clusters [101]) where the modal value of the distribution is considered as the highest level of structuring, in our case two clusters. (b) Genetic structure of populations defined by STRUCTURE software where each vertical bar represents an individual. The membership for each individual is indicated by partitioning the corresponding line into several parts with different colors. Codes correspond to locations in Figure 1 and extinct populations are shown in bold.

climatic and tidal interactions disrupt monotonic latitudinal temperature clines [54-56]. In particular, delivery of cold waters by upwelling is not directly correlated with atmospheric processes, providing an opportunity for regional de-coupling of global warming and the creation of refugial areas where intertidal communities can escape the effects of projected climatic changes $[57,58]$. Strong upwelling events off the northwest Iberian coastline reinforce latitudinal temperature gradients [32], while local upwelling further south (for example, the Cape Ghir region in Morocco, $31^{\circ} \mathrm{N}$ ) disrupts latitudinal thermal clines. The latter constitutes one of the most persistent (year-round) upwelling cells along the northwest African

Table 2 Genetic diversity of each cluster.

\begin{tabular}{lccc}
\hline & $\boldsymbol{H}_{\mathrm{E}}$ & $\hat{A}_{\mathbf{2 8 0} / \mathbf{1 9 0}} \pm$ SD $\hat{A}_{\text {280/190 }}$ & UAN \\
\hline Northern cluster & 0.6281 & $11.9 / 11.2 \pm 0.11 / 0.26$ & 16 \\
Southern cluster-past & 0.545 & $9.08 /$ n.a $\pm 0.3 /$ n.a & 4 \\
Southern cluster-present & 0.4934 & n.a./7.8 \pm n.a./0 & 3 \\
\hline
\end{tabular}

Northern cluster include locations OV, RE, LG, VN, RL, Ml, southern cluster-past include MG, TJ, RM, RF, TV, LX while southern cluster-present is formed only by extant populations of this latter clade (MG and $\mathrm{TJ}$ ). $H_{\mathrm{E}}$, expected heterozygosity; $\hat{A}_{280 / 190}$, mean allelic richness normalized to the smallest sample size of the pooled clusters $(\mathrm{N}=280 / 190) ; \mathrm{SD} \hat{A}_{280 / 190}$, standard deviation of $\hat{A}_{280 / 190}$ i UAN, unique allelic number. coast [59]. The SST data clearly indicate that the upwelling region around Cape Ghir has not experienced significant warming, in contrast to adjacent non-upwelling areas (but see below). As a result, and in contrast to the Portuguese coastline, this upwelling cell disrupts the regional thermal latitudinal cline. Despite suggestions that upwelling could provide refugia from the thermal stress of ocean warming $[57,58]$, our results show that $F$. vesiculosus populations affected by cold upwelled waters have also undergone extinction. In Cape Ghir, warming rates show variation at monthly timescales, with a significant SST increase of about $0.28^{\circ} \mathrm{C} /$ decade in March (http://coastalwarming.com[60]) and maximum SST peaking occasionally over $24^{\circ} \mathrm{C}$ [61]. Although monthly SST anomalies and high temperature events are less frequent and intense than in contiguous non-upwelling areas, they might be strong enough to cause extinction. Furthermore, effects of climate variability can be aggravated if isolation limits gene flow between populations, increasing genetic loss to drift with consequent loss of evolvability to cope with future environmental change [9]. While northern populations are well connected by continuous patches of $F$. vesiculosus, populations at the southern edge were fragmented and spatially isolated 
prior to extinction, potentially limiting population size and increasing susceptibility to drastic demographic and genetic variation.

Interestingly, patches of $F$. vesiculosus persist within the Bay of Cadiz, along the retreating front. This represents a restricted (extending less than $1 \mathrm{~km}$ along the coast) population confined to very sheltered areas within the bay (personal observation). The forecasted warming trend suggests that this small and isolated relict population faces a high risk of extinction, and this prediction is further supported by the extinction of nearby (less than $10 \mathrm{~km}$ distant) populations (for example, La Caleta and Playa de la Victoria).

\section{Range shifts in northern Iberia}

Along eastern Atlantic shores, F. vesiculosus extends its northern distributional limit in Norway, also inhabiting the northernmost and brackish regions of the Baltic Sea and in the White Sea into brackish tidal marshlands. Within the range of F. vesiculosus, there is a well-documented gap along the SW French coast (French Basque Country and Gascony) due to lack of rocky substratum [62]. In contrast to the southern clade, our results indicate that the present distributional range of the northern lineage in Iberia has been affected minimally, with a contraction of approximately $70 \mathrm{~km}$ at the southern limit of this gap (Spanish Basque Country). Notably, F. vesiculosus individuals from other regions in Europe are genetically closer to the northern Iberian clade identified in our study by the same markers [63]. A graphical model based on IPCC (Intergovernmental Panel on Climate Change; [64]) scenarios predicted the range decline observed in our study [65]. This model extends its forecast until 2050 predicting that, by 2025, cold water species, including $F$. vesiculosus, will disappear completely from the Bay of Biscay.

In Northern Spain, recent distributional declines have also been reported for Fucus serratus [66], Himanthalia elongata [67] and three kelp species [68], most probably caused by significant increases in SST [69] and unusually intense warm inflow of seawater during autumn-winter in 2006 [70]. Interestingly, despite these warming trends, present SST at the eastern limit of F. vesiculosus in Northern Spain is lower than that at the southern limit in Portugal. This suggests that the two genetic lineages have different thermal tolerances or that distinct factors are setting their distribution limit. Indeed, different genetic lineages or populations inhabiting different areas within a species' distributional range can show diverse resistance or resilience to abiotic stresses (for example, $[49,71])$. For example, along Atlantic European shores, southern edge populations of $F$. serratus are less resilient to desiccation and heat shock than central populations [49]. Future experimental approaches could allow explicit tests for signs of local adaptation between southern and northern lineages of $F$. vesiculosus.

\section{Genetic diversity under threat}

Reduction in genetic variation gives independent evidence of the severity of population and habitat contraction. Estimating losses in genetic diversity associated with habitat contraction and environmental change is one of the key challenges in biodiversity research. The intensity of genetic loss largely depends on the geographical distribution of genetic diversity within the species, including cryptic diversification. Our analyses revealed two clusters, coinciding with more northern and southern locations, distinguished by several analyses based on allele frequencies, and containing unique alleles within each group, in the five microsatellite loci here used. The differentiation between northern and southern lineages in $F$. vesiculosus was clearly established using a large number of distinct genetic markers including 13 protein coding genes [72] and 35 SNP markers [73]. The separation between these lineages of $F$. vesiculosus is older than the divergence between other more recently evolved species within the genus Fucus [71], highlighting their conservation value. The same multigene assays $[70,71]$ could not be performed on the old DNA left from the extinct populations here studied, thus our genetic analyses of the extinct populations are only based on five microsatellites, yet these were sufficient to reveal unique alleles.

The divergence between northern and southern lineages does not appear to be absolute, since a few individuals appear to occur in mixed populations (STRUCTURE analysis; for example, RE, OV, RM). Additionally, individuals from RE, not only diverge from southern populations, but emerge as the most distinct within the northern clade (CA analysis) with no apparent geographical explanation. This appears geographically unexpected, but patterns of genetic structure and differentiation are not necessarily maintained by prominent ecological/oceanographic barriers to dispersal [74]. For example, in Fucus ceranoides, distant (but relatively similar) populations do not necessarily exchange more migrants than closer (but relatively distinct) populations [18]; historical patterns of extinction and colonization may play a more important role than ongoing gene flow in determining the extent of genetic divergence between extant populations.

Presently, the distributional range of the southern clade is restricted within approximately two degrees of latitude (17\% of the historical range) and southern intra-specific genetic diversity is represented by few extant populations under threat from climatic warming. Given that predictions of future climate indicate a further rise in SST [75], there is a real risk of extinction of the southern phylogeographic 
distinctiveness owing to climatic shifts. In contrast, for long-term conservation purposes, it is reasonable to assume that, despite the relatively small range decline, the diversity of the northern clade is not under immediate risk of reduction because populations of this same genetic group are still present throughout Northern Europe.

Past and present distributional ranges of the southern lineage are characterized by markedly higher SST than those of the northern lineage; it can be hypothesized that the existence of this lineage is explained by local adaptation or phenotypic plasticity to withstand warmer waters. Our multi-locus genetic data represent neutral genetic change and do not necessarily reflect evolutionary responses to selection. However, divergent lineages often arise in areas of speciation (for example, [76,77]). Indeed, recent data indicate that the hermaphroditic species $F$. virsoides, $F$. spiralis and the recently-described F. guiryi [78] are derived from a dioecious ancestor sister to the southern clade of $F$. vesiculosus [72]. The potential loss of the cryptic southern $F$. vesiculosus lineage could end ongoing diversification (or speciation) processes and compromise the adaptive potential of the species as a whole in the face of future global warming.

In this study, genetic diversity of $F$. vesiculosus, as expressed by both gene diversity and allelic richness, was higher in northern Iberian populations than in the southern lineage. Higher genetic diversity in the northern Iberian region can be a signature of higher temporal stability of large populations while the opposite, in the southern region, could be the result of lower population sizes and/or temporal variability (that is, bottlenecks, extinctions/recolonizations) of the trailing edge populations. Higher diversity could also result from secondary contact between distinct lineages and/or from hybridization and introgression. While F. vesiculosus co-occurs with other fucoids throughout the majority of its range, including Northern Iberia, Southern Iberian individuals occur in allopatry. Therefore, hybridization events are likely only within and to the north of the contact zone between the sympatric and allopatric ranges [63]. Given the apparently small population sizes (small patches) of the populations of the southern group, which are, thus, prone to drift and bottlenecks, and their geographical isolation (separated by tens to hundreds of $\mathrm{km}$ ), it is perhaps surprising that genetic diversity, although lower, still remains so close to northern levels. Regardless of the cause behind the current within-clade diversity, their genetic distinctiveness implies that the total diversity of F. vesiculosus would be significantly reduced should these last remaining populations also become extinct.

\section{Conclusions}

A remarkable climate-induced species range reduction is driving a cryptic genetic clade (southern clade) to extinction. This clade occurs under stressful and selective environmental conditions and is, therefore, a potential pool of adaptive traits for the species; losing it could thus reduce the adaptive potential of the species, a serious conservation concern. However, the recent loss of most of the populations in this lineage suggests a more drastic scenario where their genetic distinctiveness has not been able to rescue them from extinction. Although low diversity within small marginal populations can reduce local adaptive capacity [47], here, even the southern clade hotspot of diversity (Rio Mira - RM) went extinct.

In addition to genetic erosion, the elimination of $F$. vesiculosus populations is likely to have other immediate ecological consequences. This is a dominant intertidal ecosystem engineer that influences coastal species richness by modifying habitats, increasing spatial complexity and facilitating the presence of other species $[79,80]$; thus, its large-scale disappearance may modify and decrease ecosystem complexity, reducing diversity and abundance of associated species (for example, Baltic Sea [81]), with potential effects on all trophic levels.

\section{Methods}

\section{Past and present distributions and endpoints}

Data on the past distribution and southern endpoint of $F$. vesiculosus along Atlantic North African and Iberian coastlines were gathered from a comprehensive literature review and information from herbarium collections. Data for the last decade also included personal records and associated sample collections made by our team in multiple surveys of the Iberian and Moroccan coastline for genetic sampling of this species for previous studies $[63,72,82,83]$ and of species that co-occur in the same habitats $[17,84,85]$. Published literature was screened up until May 2012 in searches using Google Scholar and ISI Web of Knowledge and based on combinations of the following keywords: Fucus, vesiculosus, Morocco, Iberia, Iberian Peninsula, Portugal, Spain, France, Atlantic, Western Sahara, distribution, herbarium, Fucales, Fucophyceae. In addition, literature reported in AlgaeBase (http://www. algaebase.org) was screened and searched up until 16 May 2012. Sampling artifacts may bias range shift studies [86] because (a) the spatial and temporal scale of surveys are limited, and (b) taxonomical information and ecology of species are poorly known. We expect these limitations to have minimal effects on our data because (a) the entire stretch of coast examined in the present study has been the object of extensive research providing a fundamental dataset of the spatial and temporal extent of the species' geographic range; and (b) F. vesiculosus is a scientifically popular species with well-known biology. It has the clear distinctive trait of possessing air bladders on the thallus, diagnostic for this species, and presents separate sexes, in 
contrast with the only other congeneric species occurring southwards from North Portugal. In addition, museum and literature records did not show any discrepancy. Therefore, we are confident about the quality of the points of reference used in this study.

Current distribution and endpoints were obtained based on an extensive field survey thoroughly covering the entire past distribution of $F$. vesiculosus. The survey was carried out during low spring tides between 2009 and 2011 on rocky intertidal shores along the Atlantic North African and Iberian coastlines. Eighty-four moderately wave exposed and estuarine locations were sampled from Hondarribia (Spain, $43^{\circ} 21^{\prime} \mathrm{N} 1^{\circ} 47^{\prime} \mathrm{W}$ ) to Dakhla (Western Sahara, $\left.23^{\circ} 41^{\prime} \mathrm{N} 15^{\circ} 55^{\prime} \mathrm{W}\right)$, covering a latitudinal extension of more than $2,150 \mathrm{~km}$. Locations of the survey were chosen based on previous reports of the presence of $F$. vesiculosus (herbarium, DNA samples and literature data). Five additional locations were only surveyed in 2009 to 2011, of which two were in Western Sahara (Boujdour and Dakhla), south of the historical southern limit.

Most of the locations were visited at least twice, covering winter and summer months, and each location included two sites from $500 \mathrm{~m}$ to $1 \mathrm{~km}$ apart. At each site, two observers performed searches lasting approximately 60 minutes across all microhabitats present.

\section{Temperature trends}

Monthly averaged SST data between January 2009 and December 2011 with a $4 \mathrm{~km}$ resolution were retrieved from the Moderate Resolution Imaging Spectroradiometer-Aqua (MODIS-Aqua) dataset available from the National Aeronautics and Space Administration (NASA) Goddard Earth Sciences (GES) Data and Information Services Center (DISC). Visualization was performed using Giovanni, a web-based application developed by the GES DISC [61].

Coastal SST warming data over the last three decades $\left({ }^{\circ} \mathrm{C} /\right.$ decade from January 1982 to December 2011) were obtained from the Worldwide Coastal Warming Assessment project website at http://www.coastalwarming.com/ index.html[60]. This project uses Advanced Very High Resolution Radiometer (AVHRR), NOAA Optimum Interpolation $1 / 4$ Degree Daily Sea Surface Temperature Analysis data (Reynolds OI V2 SST data) acquired from the NOAANational Climatic Data Center (http://www.ncdc.noaa.gov).

Note that, although warming rates at coastal and ocean locations often depend on the selected spatial and temporal scales, our SST trends are comparable with those reported in other studies that focused on different periods and spatial resolutions $[31,59,87,88]$.

\section{Genetic data}

Previously sampled $F$. vesiculosus collected in 2001 and 2002 from 12 locations, including four extinct populations, were used for genetic analyses (Figure 1). DNA extraction used the DNeasy ${ }^{\mathrm{TM}}$ Plant Mini Kit (Qiagen, Hilden, Germany) and five polymorphic microsatellite loci, L20, L58, L38, L94, L78 [89] were amplified and genotyped following the methods described in Perrin et al. [83].

\section{Data analyses}

Observed $\left(H_{\mathrm{O}}\right)$ and expected $\left(H_{\mathrm{E}}\right)$ heterozygosities were estimated, and deviations from Hardy-Weinberg equilibrium were tested for significance with 10,000 permutations, using GENETIX 4.05 software (Belkhir et al. 1996-2004), applying q-value correction for multiple tests [90]. Allelic richness $(\hat{A})$ was estimated for each population separately, standardized to 20 individuals to account for differences in sample size, using the StandArich package and R 2.10.1 software. Plot of allelic frequencies for each location and marker was performed with the above package.

To depict the global genetic variation among the samples, a CA based on the matrix of individual genotypes identified with five nuclear markers was performed using the factorial correspondence analysis (FCA) procedure on populations implemented in GENETIX 4.05 [91] and graphically visualized with IBM $^{\circledR}$ SPSS $^{\circledR} 20$ software.

$F_{S T}$ and confidence intervals were estimated between pairs of populations with the estimator $\theta$ [92], and computed using the R package 'DiveRsity' [93]. Additionally, pairwise population differentiation was calculated as estimates of Jost's $D_{\mathrm{EST}}$ [94] using SPADE software [95]. Significance was tested using 10,000 random permutations of the individuals between samples with a threshold adjusted using q-value correction for multiple comparisons.

The Cavalli-Sforza and Edwards' chord distance [96] was computed (with GENDIST), as this measure has been shown to generate higher probabilities of obtaining the correct tree topology [97]. Neighbor-joining was used to assemble the tree in NEIGHBOR with bootstrap resampling (10,000 replications) executed using SEQBOOT and CONSENSE. All programs are part of the software package PHYLIP 3.69 [98]. The output was visualized in FIGTREE 1.3.1. [99] and edited in Adobe ${ }^{\circledR}$ Illustrator $^{\circledR}$ CS4 14.0.0 (Adobe System Inc.).

STRUCTURE 2.3.3. software [100] was used to estimate the most probable number of population clusters (K). The analysis was run without prior information on populations, assuming correlated allele frequencies and admixture. The number of possible Ks assessed was 1 to 13 (maximum number of populations plus one) and 20 independent runs with 100,000 Markov Chain Monte Carlo (MCMC) iterations and 10,000 burn-in were performed at each $\mathrm{K}$ to calculate $\Delta \mathrm{K}$ as in Evanno et al. [101]. CLUMPP software [102] was subsequently used to find the optimal alignment of the 20 replicate cluster analyses of the same $\mathrm{K}$. The mean membership matrix 
across replicates was plotted with the program DISTRUCT [103].

Finally, to compare the level of diversity within clusters, estimates of $\hat{A}, H_{O}$ and $H_{E}$ were calculated for the different clusters determined by STRUCTURE analyses by pooling all populations from each cluster.

\section{Additional material}

Additional file 1: List of locations surveyed. Name and coordinates of locations surveyed during 2009-2011, ordered from north to south.

Presence/absence of the species and latest known year of its presence is also reported.

Additional file 2: Allele frequencies for locus L20. Codes correspond to locations in Figure 1, locations belonging to the southern lineage are encircled and extinct populations are shown in bold. The actual values of frequencies are represented by dots of varying diameter: allele codes are indicated on the $\mathrm{x}$ axis and population names on the $\mathrm{y}$ axis.

Additional file 3: Allele frequencies for locus L58. Codes correspond to locations in Figure 1, locations belonging to the southern lineage are encircled and extinct populations are shown in bold. The actual values of frequencies are represented by dots of varying diameter: allele codes are indicated on the $\mathrm{x}$ axis and population names on the $\mathrm{y}$ axis.

Additional file 4: Allele frequencies for locus L94. Codes correspond to locations in Figure 1, locations belonging to the southern lineage are encircled and extinct populations are shown in bold. The actual values of frequencies are represented by dots of varying diameter: allele codes are indicated on the $x$ axis and population names on the $y$ axis.

Additional file 5: Allele frequencies for locus L78. Codes correspond to locations in Figure 1, locations belonging to the southern lineage are encircled and extinct populations are shown in bold. The actual values of frequencies are represented by dots of varying diameter: allele codes are indicated on the $x$ axis and population names on the $y$ axis.

Additional file 6: Allele frequencies for locus L38. Codes correspond to locations in Figure 1, locations belonging to the southern lineage are encircled and extinct populations are shown in bold. The actual values of frequencies are represented by dots of varying diameter: allele codes are indicated on the $x$ axis and population names on the $y$ axis.

Additional file 7: Genetic differentiation between pairs of populations. Codes correspond to locations in Figure 1 and are ordered from north to south, bold characters are extinct populations. Genetic differentiations $\left(F_{S T}\right)$ were estimated with the estimator $\theta$, and are reported above the diagonal while Jost's $D_{\text {EST }}$ are reported below the diagonal. All values are significant at $P<0.001$ after multiple test correction.

Additional file 8: Confidence intervals of the genetic differentiation between pairs of populations. Codes correspond to locations in Figure 1 and are ordered from north to south, bold characters are extinct populations. Confidence intervals of genetic differentiation $\left(F_{S T}\right)$ are reported above the diagonal.

\section{Abbreviations}

$\hat{A}$ : allelic richness; CA: correspondence analyses; $F_{15}$ : inbreeding coefficient; $\mathrm{F}_{\text {ST: }}$ genetic differentiation; FCA: factorial correspondence analysis; $\mathrm{H}_{\mathrm{E}}$ : expected heterozygosity; $\mathrm{H}_{\mathrm{O}}$ : observed heterozygosity; $\mathrm{K}$ : population clusters; MODIS-Aqua: Moderate Resolution Imaging Spectroradiometer-Aqua; SNP single nucleotide polymorphism; SST: sea surface temperature.

\section{Authors' contributions}

GIZ, KRN, EAS and GAP conceived and designed the study. EAS and GAP provided distribution records and genetic data for extinct populations. GIZ and KRN gathered and analyzed temperature and distribution data. ST and KRN analyzed genetic data and all authors interpreted the data. KRN and GIZ wrote the article, which was critically revised by EAS and GAP. All authors read and approved the final version.

\section{Competing interests}

The authors declare that they have no competing interests.

\section{Acknowledgements}

We thank C. Engel, C. Daguin and M. Valente for collecting samples in Portugal, F. Alberto and C. Perrin for collecting samples in Morocco, and C. Perrin, M. van de Vliet and M. Valente for the genotyping work. We thank R. Castilho for computing assistance and four referees that contributed toward improving the manuscript. This work was financed by FCT (Fundação para a Ciência e a Tecnologia), mainly through the projects PTDC/MAR/110251/ 2009 (to KRN), PTDC/AAC-CLI/109108/2008 (to EAS), and other projects (to EAS, GAP) in which some previous samples or data records had been collected. KRN was funded by FCT postdoctoral grant SFRH/BPD/45544/2008 and the collaborators described above were funded by FCT and the European Social Fund.

Received: 2 October 2012 Accepted: 23 January 2013

Published: 23 January 2013

\section{References}

1. Thomas CD, Cameron A, Green RE, Bakkenes M, Beaumont LJ, Collingham YC, Erasmus BFN, de Siqueira MF, Grainger A, Hannah L, Hughes L, Huntley B, Van Jaarsveld AS, Midgley GF, Miles L, OrtegaHuerta MA, Peterson AT, Phillips OL, Williams SE: Extinction risk from climate change. Nature 2004, 427:145-148.

2. Rubidge EM, Patton JL, Lim M, Burton AC, Brashares JS, Moritz C: Climateinduced range contraction drives genetic erosion in an alpine mammal. Nat Climate Change 2012, 2:285-288.

3. Parmesan C, Yohe G: A globally coherent fingerprint of climate change impacts across natural systems. Nature 2003, 421:37-42.

4. Sunday JM, Bates AE, Dulvy NK: Thermal tolerance and the global redistribution of animals. Nat Climate Change 2012, 2:686-690.

5. Chen I-C, Hill JK, Ohlemüller R, Roy DB, Thomas CD: Rapid range shifts of species associated with high levels of climate warming. Science 2011, 333:1024-1026.

6. Stenseth NC, Mysterud A, Ottersen G, Hurrell JW, Chan K-S, Lima M: Ecological effects of climate fluctuations. Science 2002, 297:1292-1296.

7. Hewitt GM: Genetic consequences of climatic oscillations in the Quaternary. Philos Trans R Soc London B Biol Sci 2004, 359:183-195.

8. Alsos IG, Ehrich D, Thuiller W, Eidesen PB, Tribsch A, Schönswetter $P$, Lagaye C, Taberlet P, Brochmann C: Genetic consequences of climate change for northern plants. Proc Biol Sci 2012, 279:2042-2051.

9. Jump AS, Peñuelas J: Running to stand still: adaptation and the response of plants to rapid climate change. Ecol Lett 2005, 8:1010-1020.

10. Schönswetter P, Elven R, Brochmann C: Trans-Atlantic dispersal and largescale lack of genetic structure in the circumpolar, arctic-alpine sedge Carex bigelowii s. I. (Cyperaceae). Am J Bot 2008, 95:1006-1014.

11. Ehrich D, Gaudeul M, Assefa A, Koch MA, Mummenhoff K, Nemomissa S, Intrabiodiversity Consortium, Brochmann C: Genetic consequences of Pleistocene range shifts: contrast between the Arctic, the Alps and the East African mountains. Mol Ecol 2007, 16:2542-2559.

12. Hampe A, Petit RJ: Conserving biodiversity under climate change: the rear edge matters. Ecol Lett 2005, 8:461-467.

13. Eckert CG, Samis KE, Lougheed SC: Genetic variation across species' geographical ranges: the central-marginal hypothesis and beyond. Mol Ecol 2008, 17:1170-1188.

14. Marko PB, Hoffman JM, Emme SA, McGovern TM, Keever CC, Nicole Cox L: The 'Expansion-Contraction' model of Pleistocene biogeography: rocky shores suffer a sea change? Mol Ecol 2010, 19:146-169.

15. Provan J, Bennett KD: Phylogeographic insights into cryptic glacial refugia. Trends Ecol Evol 2008, 23:564-571.

16. Provan J, Maggs CA: Unique genetic variation at a species's rear edge is under threat from global climate change. Proc Biol Sci 2011, 279:39-47.

17. Diekmann $\mathrm{OE}$, Serrão EA: Range-edge genetic diversity: locally poor extant southern patches maintain a regionally diverse hotspot in the seagrass Zostera marina. Mol Ecol 2012, 21:1647-1657.

18. Neiva J, Pearson GA, Valero M, Serrão EA: Drifting fronds and drifting alleles: range dynamics, local dispersal and habitat isolation shape the population 
structure of the estuarine seaweed Fucus ceranoides. J Biogeogr 2012, 39:1167-1178.

19. Pérez-Ruzafa I, Gallardo T, Gómez-Cancio R: Numerical taxonomy of taxa of the genus Fucus in the Iberian Peninsula. Hydrobiologia 1993, 260/261:81-90

20. Navarro MJ, Gallardo T: Aportación al conocimiento de la flora bentónica marina de las costas de Huelva. Stud Bot 1994, 13:51-60.

21. Lima FP: Biogeography of Intertidal Species along the Portuguese Rocky Coast Saarbrücken, Germany: Lambert Academic Publishing; 2010.

22. Boaventura D, Ré P, Cancela da Fonseca L, Hawkins SJ: Intertidal rocky shore communities of the continental Portuguese coast: analysis of distribution patterns. Marine Ecol 2002, 23:69-90.

23. Pereira S, Lima F, Queiroz N, Ribeiro P, Santos A: Biogeographic patterns of intertidal macroinvertebrates and their association with macroalgae distribution along the Portuguese coast Marine Biodiversity. In Marine Biodiversity: Patterns and Processes, Assessment, Threats, Management and Conservation. Edited by: Martens K, Queiroga H, Cunha M, Cunha A, Moreira M, Quintino V, Rodrigues A, Seroôdio J, Warwick R, Dumont HJ. Dordrecht: Springer Netherlands; 2006:185-192, [Dumont HJ (Series Editor): Developments in Hydrobiology, vol.183.].

24. Fischer-Piétte E: Sur des déplacements de frontières biogéographiques, observés au long des côtes ibériques dans le domaine intercotidal. Publicaciones del Instituto de Biología Aplicada 1957, 26:35-40.

25. Ardré F: Contribution à l'étude des algues marines du Portugal I. Portugaliae Acta Biologica (B) 1970

26. Ardré F: Contribution à l'étude des algues marines du Portugal Il Biarritz: Bulletin du Centre d'Etudes et de Recherches Scientifiques; 1971.

27. Kazzaz M, Riadi H: Inventaire bibliographique des algues benthiques du littoral marocain I, Chlorophyceae et Phaeophyceae. Inventaire bibliographique des algues benthiques du littoral marocain I, Chlorophyceae et Phaeophyceae Universidad de Málaga: Departamento de biología Vegetal; 1998.

28. Rodriguez GMC, Hernandez SJS: Notas ficologicas acerca de la Costa Atlántica-marroquí. Vieraea 1986, 16:193-198.

29. Cunha AH, Assis JF, Serrão EA: Seagrasses in Portugal: a most endangered marine habitat. Aquat Bot 2012, 104:193-203.

30. Assis J, Tavares D, Tavares JT, Cunha AH, Alberto F, Serrão EA: Findkelp, a GIS-based community participation project to assess Portuguese kelp conservation status. J Coast Res 2009, 56:1469-1473.

31. Berke SK, Mahon AR, Lima FP, Halanych KM, Wethey DS, Woodin SA: Range shifts and species diversity in marine ecosystem engineers: patterns and predictions for European sedimentary habitats. Global Ecol Biogeogr 2010, 19:223-232.

32. Lima FP, Queiroz N, Ribeiro PA, Hawkins SJ, Santos AM: Recent changes in the distribution of a marine gastropod, Patella rustica Linnaeus, 1758, and their relationship to unusual climatic events. J Biogeogr 2006, 33:812-822.

33. Lourenço C, Nicastro KR, Serrão EA, Zardi GI: First record of the brown mussel (Perna perna) from the European Atlantic coast. Mar Biodivers Rec 2012, 5:e39.

34. Breeman AM: Expected effects of changing seawater temperatures on the geographic distribution of seaweed species. In Expected effects of climate change on marine coastal ecosystems. Edited by: Beukema JJ, Wolff WJ, Brouns M. The Netherlands: Kluwer Academic Publishers; 1990:69-76.

35. Wethey DS: Biogeography, competition, and microclimate: the barnacle Chthamalus fragilis in New England. Integr Comp Biol 2002, 42:872-880.

36. Jones SJ, Southward AJ, Wethey DS: Climate change and historical biogeography of the barnacle Semibalanus balanoides. Glob Ecol Biogeogr 2012, 21:716-724.

37. Lima FP, Ribeiro PA, Queiroz N, Hawkins SJ, Santos AM: Do distributional shifts of northern and southern species of algae match the warming pattern? Glob Change Biol 2007, 13:2592-2604.

38. Martínez B, Viejo RM, Carreño F, Aranda SC: Habitat distribution models for intertidal seaweeds: responses to climatic and non-climatic drivers. J Biogeogr 2012, 39:1877-1890.

39. Easterling DR, Meehl GA, Parmesan C, Changnon SA, Karl TR, Mearns LO: Climate extremes: observations, modeling, and impacts. Science 2000, 289:2068-2074.

40. van den Hoek C: Phytogeographic distribution groups of benthic marine algae in the North Atlantic Ocean. A review of experimental evidence from life history studies. Helgoland Mar Res 1982, 35:153-214.
41. Walther G-R, Post E, Convey P, Menzel A, Parmesan C, Beebee TJC, Fromentin J-M, Hoegh-Guldberg O, Bairlein F: Ecological responses to recent climate change. Nature 2002, 416:389-395.

42. King DA: Climate change science: adapt, mitigate, or ignore? Science 2004, 303:176-177.

43. Broitman BR, Navarrete SA, Smith F, Gaines SD: Geographic variation of southeastern Pacific intertidal communities. Mar Ecol Prog Ser 2001, 224:21-24.

44. Fujita RM, Wheeler PA, Edwards RL: Assessment of macroalgal nitrogen limitation in a seasonal upwelling region. Mar Ecol Prog Ser 1989, 3:293-303.

45. Rivadeneira MM, Fernández M: Shifts in southern endpoints of distribution in rocky intertidal species along the south-eastern Pacific coast. J Biogeogr 2005, 32:203-209.

46. Jones SJ, Lima FP, Wethey DS: Rising environmental temperatures and biogeography: poleward range contraction of the blue mussel, Mytilus edulis L., in the western Atlantic. J Biogeogr 2010, 37:2243-2259.

47. Blanchette CA, Melissa Miner C, Raimondi PT, Lohse D, Heady KEK, Broitman BR: Biogeographical patterns of rocky intertidal communities along the Pacific coast of North America. J Biogeogr 2008, 35:1593-1607.

48. Fuller A, Dawson T, Helmuth B, Hetem RS, Mitchell D, Maloney SK Physiological mechanisms in coping with climate change. Physiol Biochem Zool 2010, 83:713-720.

49. Pearson GA, Lago-Leston A, Mota C: Frayed at the edges: selective pressure and adaptive response to abiotic stressors are mismatched in low diversity edge populations. J Ecol 2009, 97:450-462.

50. Nicastro K, Zardi G, McQuaid C, Stephens L, Radloff S, Blatch G: The role of gaping behaviour in habitat partitioning between coexisting intertidal mussels. BMC Ecol 2010, 10:17.

51. Helmuth B, Mieszkowska N, Moore P, Hawkins SJ: Living on the edge of two changing worlds: forecasting the responses of rocky intertidal ecosystems to climate change. Annu Rev Ecol Evol Syst 2006, 37:373-404.

52. Seabra R, Wethey DS, Santos AM, Lima FP: Side matters: microhabitat influence on intertidal heat stress over a large geographical scale. J Exp Mar Biol Ecol 2011, 400:200-208.

53. Hengeveld R, Haeck J: The distribution of abundance. I. Measurements. J Biogeogr 1982, 9:303-316.

54. Sagarin RD, Gaines SD: The 'abundant centre' distribution: to what extent is it a biogeographical rule? Ecol Lett 2002, 5:137-147.

55. Sagarin RD, Gaines SD, Gaylord B: Moving beyond assumptions to understand abundance distributions across the ranges of species. Trends Ecol Evol 2006, 21:524-530.

56. Sagarin RD, Gaines SD: Geographical abundance distributions of coastal invertebrates: using one-dimensional ranges to test biogeographic hypotheses. J Biogeogr 2002, 29:985-997.

57. Riegl B, Piller WE: Possible refugia for reefs in times of environmental stress. Int J Earth Sci 2003, 92:520-531.

58. Greenstein BJ, Pandolfi JM: Escaping the heat: range shifts of reef coral taxa in coastal Western Australia. Glob Change Biol 2008, 14:513-528.

59. McGregor HV, Dima M, Fischer HW, Mulitza S: Rapid 20th-century increase in coastal upwelling off northwest Africa. Science 2007, 315:637-639.

60. Lima FP, Wethey DS: Three decades of high-resolution coastal sea surface temperatures reveal more than warming. Nat Commun 2012, 3:704.

61. Acker JG, Leptoukh G: Online analysis enhances use of NASA earth science data. Eos 2007, 88:14-17.

62. Lüning K: Seaweeds. Their environment, biogeography, and ecophysiology New York: Wiley Interscience; 1990.

63. Moalic Y, Arnaud-Haond S, Perrin C, Pearson G, Serrao E: Traveling in time with networks: revealing present day hybridization versus ancestral polymorphism between two species of brown algae, Fucus vesiculosus and F. spiralis. BMC Evol Biol 2011, 11:33.

64. IPCC: Climate change The Scientific Basis, Cambridge University Press; 2001.

65. Alcok R: The effects of climate change on rocky shore communities in the Bay of Biscay, 1895-2050. Ph.D. Thesis University of Southampton, UK; 2003.

66. Viejo RM, Martínez B, Arrontes J, Astudillo C, Hernández L: Reproductive patterns in central and marginal populations of a large brown seaweed: drastic changes at the southern range limit. Ecography 2010, 34:75-84.

67. Fernandez C, Anadon R: La cornisa cantabrica: un escenario de cambios de distribución de comunidades intermareales. Algas 2008, 39:30-32.

68. Fernández C: The retreat of large brown seaweeds on the north coast of Spain: the case of Saccorhiza polyschides. Eur J Phycol 2011, 46:352-360. 
69. Gómez-Gesteira M, deCastro M, Alvarez I, Gómez-Gesteira JL: Coastal sea surface temperature warming trend along the continental part of the Atlantic Arc (1985-2005). J Geophys Res 2008, 113:C04010.

70. Le Cann B, Serpette A: Intense warm and saline upper ocean inflow in the southern Bay of Biscay in autumn-winter 2006-2007. Cont Shelf Res 2009, 29:1014-1025.

71. Zardi Gl, Nicastro KR, McQuaid CD, Hancke L, Helmuth B: The combination of selection and dispersal helps explain genetic structure in intertidal mussels. Oecologia 2011, 165:947-958.

72. Canovas F, Mota CF, Serrão EA, Pearson GA: Driving south: a multi-gene phylogeny of the brown algal family Fucaceae reveals relationships and recent drivers of a marine radiation. BMC Evol Biol 2011, 11:371.

73. Canovas F, Mota C, Ferreira-Costa J, Serrão E, Coyer J, Olsen J, Pearson G: Development and characterization of 35 single nucleotide polymorphism markers for the brown alga Fucus vesiculosus. Eur J Phycol 2011, 46:342-351.

74. Pelc RA, Warner RR, Gaines SD: Geographical patterns of genetic structure in marine species with contrasting life histories. J Biogeogr 2009, 36:1881-1890.

75. IPCC: Climate change 2007: synthesis report. Contribution of working groups I, II, and III to the fourth assessment report of the Intergovernmental Panel on Climate Change. Geneva, Switzerland; 2007, 104.

76. Teske P, Papadopoulos I, Newman B, Dworschak P, McQuaid C, Barker N: Oceanic dispersal barriers, adaptation and larval retention: an interdisciplinary assessment of potential factors maintaining a phylogeographic break between sister lineages of an African prawn. BMC Evol Biol 2008, 8:341.

77. Ribera I, Castro A, Díaz JA, Garrido J, Izquierdo A, Jäch MA, Valladares LF: The geography of speciation in narrow-range endemics of the 'Haenydra' lineage (Coleoptera, Hydraenidae, Hydraena). J Biogeogr 2011, 38:502-516.

78. Zardi Gl, Nicastro KR, Canovas F, Ferreira Costa J, Serrão EA, Pearson GA: Adaptive traits are maintained on steep selective gradients despite gene flow and hybridization in the intertidal zone. PLOS ONE 2011, 6:e19402.

79. Seed R, O'Connor RJ: Community organization in marine algal epifaunas. Annu Rev Ecol Syst 1981, 12:49-74.

80. Hay ME: Associational plant defenses and the maintenance of species diversity: turning competitors into accomplices. Am Nat 1986, 128:617-641.

81. Wikström SA, Kautsky L: Structure and diversity of invertebrate communities in the presence and absence of canopy-forming Fucus vesiculosus in the Baltic Sea. Estuar Coast Shelf Sci 2007, 72:168-176.

82. Coyer JA, Hoarau G, Costa JF, Hogerdijk B, Serrão EA, Billard E, Valero M, Pearson GA, Olsen JL: Evolution and diversification within the intertidal brown macroalgae Fucus spiralis/F. vesiculosus species complex in the North Atlantic. Mol Phylogenet Evol 2011, , 58: 283-296.

83. Perrin C, Daguin C, Vliet MVD, Engel CR, Pearson GA, Serrão EA: Implications of mating system for genetic diversity of sister algal species: Fucus spiralis and Fucus vesiculosus (Heterokontophyta, Phaeophyceae). Eur J Phycol 2007, 42:219-230.

84. Diekmann O, Coyer JA, Ferreira J, Olsen JL, Wytze TS, Pearson GA, Serrão EA: Population genetics of Zostera noltii along the west Iberian coast: consequences of small population size, habitat discontinuity and near-shore currents. Mar Ecol Prog Ser 2005, 290:89-96.

85. Diekmann O, Gouveia L, Perez J, Gil-Rodriguez C, Serrão E: The possible origin of Zostera noltii in the Canary Islands and guidelines for restoration. Mar Biol 2010, 157:2109-2115.

86. Lonhart SI, Tupen JW: New range records of 12 marine invertebrates: the role of El Nino and other mechanisms in Southern and Central California. Bull South Cal Acad Sci 2001, 100:238-248.

87. Gómez-Gesteira M, De Castro M, Álvarez I, Lorenzo MN, Gesteira JLG, Crespo AJC: Spatio-temporal upwelling trends along the Canary upwelling system (1967-2006). Ann NY Acad Sci 2008, 1146:320-337.

88. Relvas P, Luís J, Santos AMP: Importance of the mesoscale in the decadal changes observed in the northern Canary upwelling system. Geophys Res Lett 2009, 36:L22601

89. Engel CR, Brawley SH, Edwards KJ, Serrão EA: Isolation and cross-species amplification of microsatellite loci from the fucoid seaweeds Fucus vesiculosus, F. serratus and Ascophyllum nodosum (Heterokontophyta, Fucaceae). Mol Ecol Notes 2003, 3:180-182.
90. Storey JD: A direct approach to false discovery rates. J R Stat Soc Series B Stat Methodol 2002, 64:479-498.

91. Belkhir K, Borsa P, Chikhi L, Raufaste N, Bonhomme F: GENETIX 4.05, logiciel sous Windows TM pour la génétique des populations. Laboratoire Génome, Populations, Interactions, CNRS UMR 5000, Université de Montpellier II, Montpellier, France; 1996, 2004.

92. Weir BS, Cockerham CC: Estimation of gene flow from F-statistics. Evolution 1984, 47:855-863.

93. Keenan K: Genetic diversity partition statistics and informative locus selection using Fst, Gst, Dest(Jost Chao) G'st and In. 2013.

94. Jost LOU: GST and its relatives do not measure differentiation. Mol ECol 2008, 17:4015-4026.

95. Chao A, Shen T-J: SPADE (Species Prediction and Diversity Estimation). SPADE (Species Prediction and Diversity Estimation) National Chung Hsing University; 2010.

96. Cavalli-Sforza LL, Edwards AWF: Phylogenetic analysis: models and estimation procedures. Evolution 1967, 21:550-570.

97. Takezaki N, Nei M: Genetic distances and reconstruction of phylogenetic trees from microsatellite DNA. Genetics 1996, 144:389-399.

98. Felsenstein J, Ed: PHYLIP (Phylogeny Inference Package) version 3.69. Seattle: Distributed by the author. Department of Genetics. University of Washington; 1993.

99. Rambaut A: FigTree. Institute of Evolutionary Biology, University of Edinburgh; 1.3.1 2009.

100. Pritchard JK, Stephens M, Donnelly P: Inference of population structure using multilocus genotype data. Genetics 2000, 155:945-959.

101. Evanno G, Regnaut S, Goudet J: Detecting the number of clusters of individuals using the software structure: a simulation study. $\mathrm{Mol}$ Ecol 2005, 14:2611-2620.

102. Jakobsson M, Rosenberg NA: CLUMPP: a cluster matching and permutation program for dealing with label switching and multimodality in analysis of population structure. Bioinformatics 2007, 23:1801-1806.

103. Rosenberg NA: Distruct: a program for the graphical display of population structure. Mol Ecol Notes 2004, 4:137-138.

doi:10.1186/1741-7007-11-6

Cite this article as: Nicastro et al: Shift happens: trailing edge

contraction associated with recent warming trends threatens a distinct genetic lineage in the marine macroalga Fucus vesiculosus. BMC Biology 2013 11:6.

\section{Submit your next manuscript to BioMed Central and take full advantage of:}

- Convenient online submission

- Thorough peer review

- No space constraints or color figure charges

- Immediate publication on acceptance

- Inclusion in PubMed, CAS, Scopus and Google Scholar

- Research which is freely available for redistribution

Submit your manuscript at www.biomedcentral.com/submit 